\title{
Rapid Pacing Using the Guidewire During Transcatheter Tricuspid Valve-in-Valve Implantation
}

\author{
Amnon Eitan, $\mathrm{MD}^{*}$, Ariel Roguin, $\mathrm{MD}$, PhD, Arthur Kerner, $\mathrm{MD}$ \\ Cardiology Department, Rambam Medical Center, Haifa, Israel
}

\begin{abstract}
Transcatheter valve replacement is now widely used to treat high-risk patients. This approach is also expanding to the tricuspid valve, mostly for "valve-invalve" and "valve-in-ring" implantations. Rapid pacing during transcatheter valve implantation is used to reduce cardiac output and minimize the risk of valve dislodgement. Rapid pacing is usually done using the patient's permanent pacemaker or a temporary pacing electrode that is usually introduced retrogradely into the left ventricle or coronary sinus. Here, we describe the use of the tricuspid valve-in-valve implantation super-stiff guidewire for rapid pacing during implantation of the valve. This approach may obviate the need for ancillary steps that may increase procedure time, $\mathrm{X}$-ray exposure, and risk of complications.

Copyright $\odot 2017$ Science International Corp.
\end{abstract}

\section{Key Words}

Tricuspid valve-in-valve $\bullet$ Rapid pacing

\section{Introduction}

It is well recognized today that significant tricuspid valve regurgitation is associated with poor prognosis [1, 2]. The long-term results of tricuspid surgical repairs are suboptimal, with more than $25 \%$ of patients developing progressive moderate or severe valve regurgitation within 5 years of repair $[3,4]$. Similar to bioprostheses in other positions, tricuspid valve bioprostheses are prone to degeneration and dysfunction.

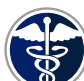

Fax +1 2037853346

E-Mail: jshd@scienceinternational.org

http://structuralheartdisease.org/

\author{
(c) 2017 Journal of Structural Heart Disease \\ Published by Science International Corp. \\ ISSN 2326-4004 \\ Accessible online at: \\ http://structuralheartdisease.org/
}

Tricuspid valve prosthesis longevity may be shorter than that of bioprosthetic valves in the systemic circulation, with $75 \%$ to $83 \%$ freedom from reintervention at $8-10$ years and $<60 \%$ at 15 years [5-7].

Transcatheter valve replacement is now widely utilized to treat high-risk patients with native valve disease and is expanding to encompass degenerated bioprosthetic valves. There are several reports of transcatheter tricuspid "valve-in-valve" and "valve-inring" implantations with reasonable short- and medium-term results $[8,9]$.

Rapid pacing during transcatheter valve implantation is used to reduce cardiac output and minimize the risk of valve dislodgement. Although the lower pressure in the right ventricle may reduce the need for rapid pacing during valve implantation, it is used in most cases when the Sapien valve is implanted [8, 9]. Rapid pacing is usually done using the patient's permanent pacemaker or a temporary pacing electrode. The pacing electrode is usually introduced retrogradely into the left ventricle or coronary sinus; other positions used are the right atrium or right ventricle $[8,9]$. Placing a pacing electrode in the left ventricle requires additional arterial access. Any positioning of a dedicated pacing electrode is time-consuming and involves additional X-ray exposure. However, several published reports describe successful and safe rapid pacing using the left ventricle guidewire during valve implantation in transcatheter aortic valve replacement (TAVR) $[10,11]$.
* Corresponding Author:

Amnon Eitan, MD

Department of Cardiology

Rambam Medical Center

7 Efron Street, PO Box 9602, Haifa 31096, Israel

Tel.: +972 4777 2181; Fax: +972 4777 3451; E-Mail: eitancardio@gmail.com 
Here, we report the use of the tricuspid valve-invalve implantation super-stiff guidewire for rapid pacing during implantation of the valve.

\section{Case Presentation}

A 57-year-old woman underwent mechanical aortic valve and mitral valve replacement and bio-prosthetic tricuspid valve replacement $(27 \mathrm{~mm}$ Carpentier-Edwards, CE) in 2006 due to rheumatic heart disease. With time, she gradually developed severe stenosis of the tricuspid bio-prosthesis. The mean and peak pressure gradients over the tricuspid bio-prosthetic valve were 26 and $35 \mathrm{mmHg}$, respectively, with normal left ventricular and right ventricular systolic function as evaluated by echocardiography. She complained of shortness of breath with mild effort and edema of her legs. Her functional capacity was assessed as NYHA III-IV/IV.

During pre-procedural evaluation, the patient had a body weight of $62 \mathrm{~kg}$ and height of $155 \mathrm{~cm}$, blood creatinine $0.73 \mathrm{mg} \%$, and an estimated glomerular filtration rate of $83 \mathrm{ml} / \mathrm{min}$. The patient had a logistic EUROSCORE-II of $4 \%$ and STS scores of $2.1 \%$ for mortality and $17.9 \%$ for morbidity/ mortality.

Considering the patient's high risk in re-operation, we decided to proceed to tricuspid valve-invalve implantation. The procedure was performed with the patient under deep sedation. Using a JR4 catheter, the tricuspid valve was crossed with a long hydrophilic wire that was advanced to the left pulmonary artery. The wire was replaced by an Amplatz super-stiff 0.035" wire. An Edwards Sapien S3 26 mm valve was positioned over the wire in the bio-prosthetic tricuspid valve. After advancing the transcatheter tricuspid valve implantation (TTVI) system to the implantation position, an external cardiac pacemaker was connected to the guidewire. One electrode of the pacemaker was connected to the Amplatz super-stiff wire (Figure 1), and the other electrode was connected to a large suture needle that was placed

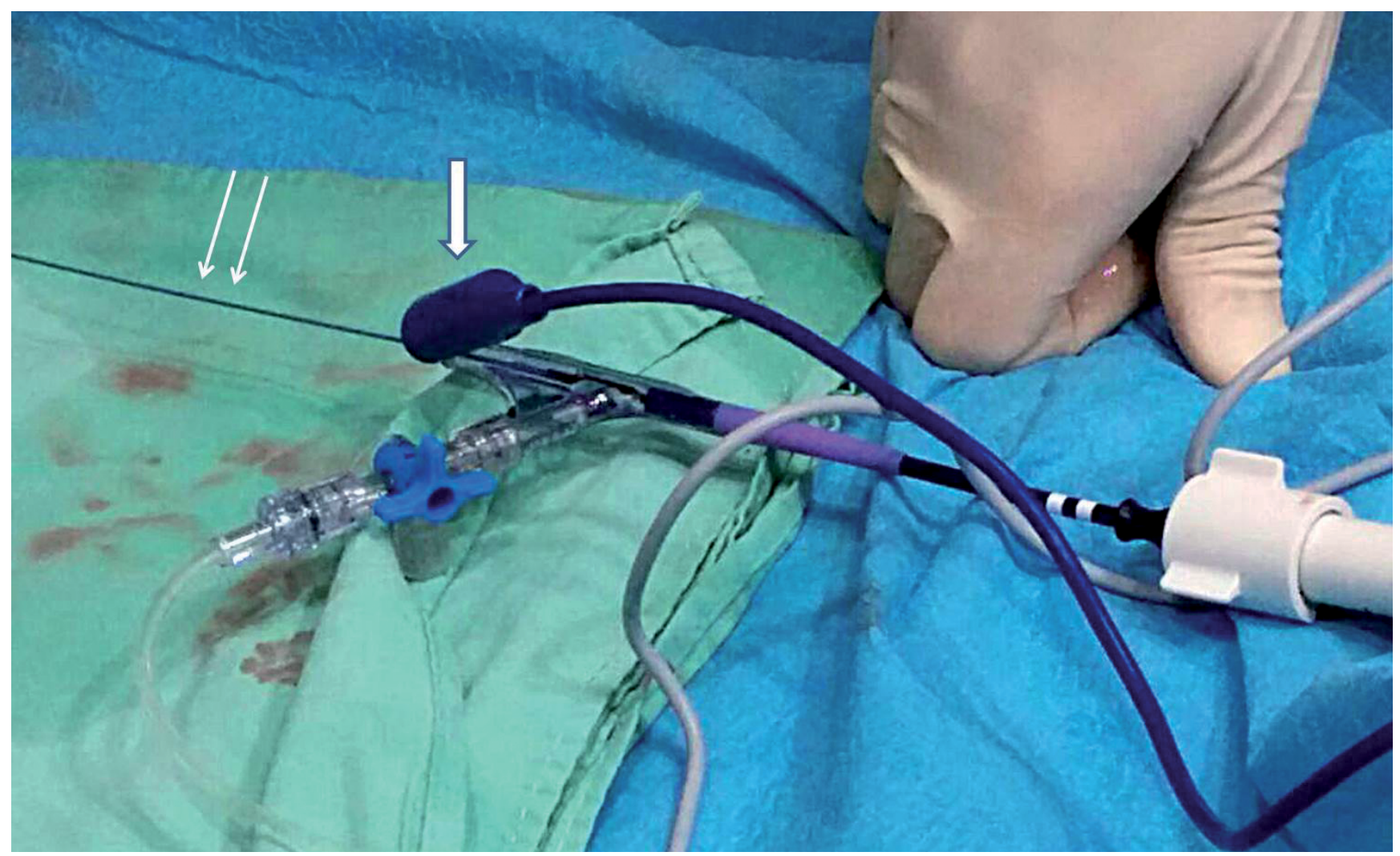

Figure 1. Pacemaker electrode (thick arrow) connected to the Amplatz super-stiff guidewire (thin arrows). 


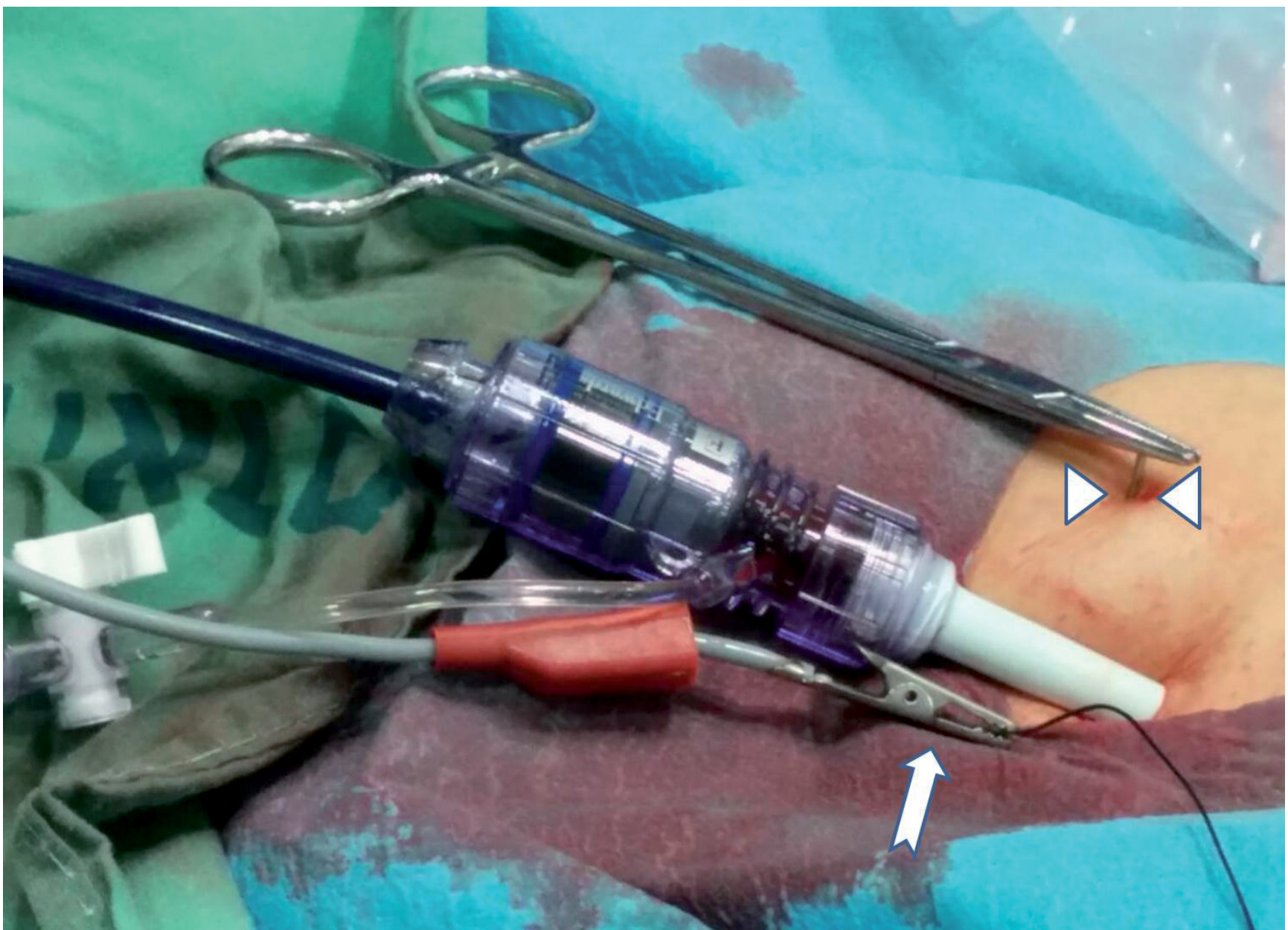

Figure 2. Pacemaker electrode (arrow) connected to a large suture needle (between arrowheads) placed trans-cutaneously in the right groin.

trans-cutaneously in the right groin (Figure 2). During rapid pacing at a rate of 160 beats per minute, the valve was expanded with slow inflation in the correct position (Figure 3). Following implantation, pacing was stopped (Figure 4).

Trans-thoracic echocardiography after the procedure showed no para-valvular leak and a trans-valve mean gradient of $5 \mathrm{mmHg}$. The procedure time was $1.5 \mathrm{~h}$, and fluoroscopy time was $12.5 \mathrm{~min}$.

\section{Discussion}

Rapid pacing during valve implantation in a bio-prosthetic valve or ring is usually used when a balloon-expandable valve is used. In our case, valve implantation was performed in a patient with a me- chanical aortic valve, excluding the option of placing a pacing electrode retrogradely into the left ventricle. Pacing the right atrium is possible but may be unreliable and may not supply sufficient ventricular rhythm.

Two reports by Faurie et al. and Hilling-Smith et al. described successful and safe rapid pacing using the guidewire during TAVR. During TAVR, the guidewire is positioned in the left ventricle apex and has good contact with the myocardium. We describe good pacing capture while using the guidewire positioned through the outflow of the right ventricle and into the pulmonary artery.

In the VIVID registry [9], which is a large international registry of TTVI, rapid pacing during valve implantation was used mostly during Sapien 


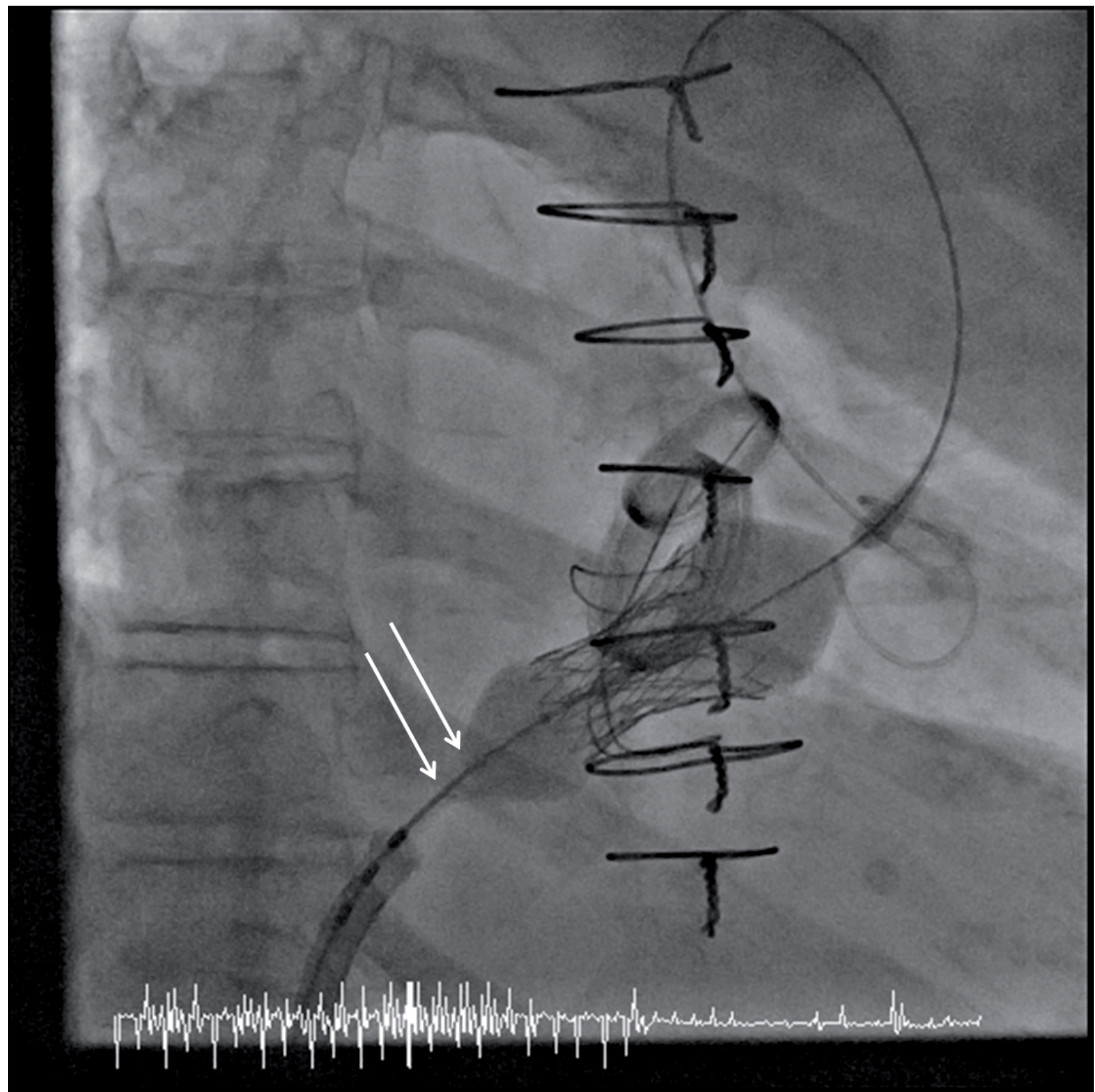

Figure 3. Rapid pacing (see rhythm strip at bottom) through the Amplatz super-stiff guidewire (arrows) positioned through the tricuspid valve in the right ventricle into the pulmonary artery during implantaion of a Sapien S3 valve.

valve implantation. Pacing was performed through existing leads or with a temporary pacing catheter/ wire, most often introduced retrogradely into the left ventricle or coronary sinus. Only one patient out of 156 had complete atrio-ventricular block requiring a permanent pacemaker; therefore, it seems there is no need for a back-up pacing electrode during TTVI in valve. Rapid pacing using the guidewire as a unipolar electrode saves puncture of the femoral artery for retrograde left ventricular pacing.

In a report of 22 patients with tricuspid valve regurgitation who underwent catheterization 


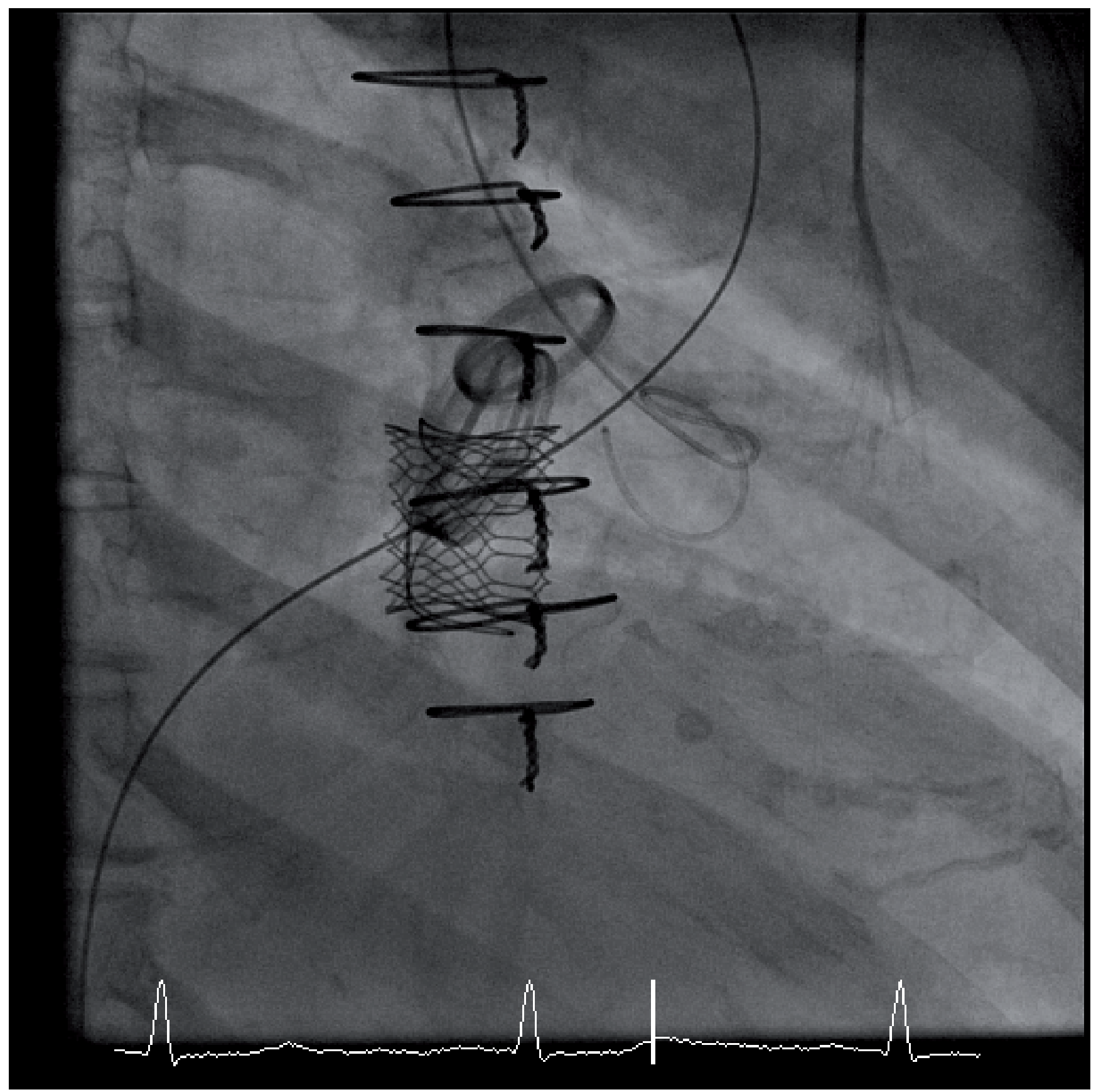

Figure 4. Final result after valve implantation in a correct position.

with the intent to perform transcatheter tricuspid valve-in-ring implantation [8], rapid pacing was implemented in $56 \%$ of cases via an existing pacing system $(n=9)$ or a transvenous atrial pacing wire $(n=2)$. In four patients with a transvenous right ventricular pacing lead traversing the tricuspid valve annulus, the lead was entrapped by the tricuspid valve-in-ring implantation. In one patient, the right ventricular lead was dislodged, although that patient did not require ventricular pacing.

Rapid pacing using the guidewire allows a reliable right ventricular pacing method without the risk of electrode entrapment. Due to the need for isolation of 
the wire, pacing can be performed only after delivering the TTVI system over the wire.

In conclusion, rapid pacing during TTVI using the guidewire as a unipolar electrode is feasible, safe, and easy to perform. It may shorten the duration of and save unnecessary steps during the procedure.

\section{Conflict of Interest}

The authors have no conflict of interest relevant to this publication.

\section{Comment on this Article or Ask a Question}

\section{References}

1. Antunes MJ, Barlow JB. Management of tricuspid valve regurgitation. Heart. 2007;93:271-276. DOI: 10.1136/ hrt.2006.095281

2. Nath J, Foster E, Heidenreich PA. Impact of tricuspid regurgitation on long-term survival. J Am Coll Cardiol. 2004;43:405-409. DOI: 10.1016/j.jacc.2003.09.036

3. Jeganathan R, Armstrong S, Al-Alao B, David $T$. The risk and outcomes of reoperative tricuspid valve surgery. Ann Thorac Surg. 2013;95:119-124. DOI: 10.1016/j.athoracsur.2012.08.058

4. McCarthy PM, Bhudia SK, Rajeswaran J, Hoercher KJ, Lytle BW, Cosgrove DM, et al. Tricuspid valve repair: durability and risk factors for failure. J Thorac Cardiovasc Surg. 2004;127:674-685. DOI: 10.1016/j. jtcvs.2003.11.019

5. 5. Chang B-C, Lim S-H, Yi G, Hong YS, Lee $\mathrm{S}$, Yoo K-J, et al. Long-term clinical results of tricuspid valve replacement. Ann Thorac Surg. 2006;81:1317-1324. DOI: 10.1016/j. athoracsur.2005.11.005

6. Guenther T, Noebauer C, Mazzitelli D, Busch R, Tassani-Prell P, Lange R. Tricuspid valve surgery: a thirty-year assessment of early and late outcome. Eur J Cardiothorac Surg. 2008;34:402-409. DOI: 10.1016/j. ejcts.2008.05.006

7. Marquis-Gravel G, Bouchard D, Perrault $L P$, Pagé $P$, Jeanmart $H$, Demers $P$, et al. Retrospective cohort analysis of 926 tricuspid valve surgeries: clinical and hemodynamic outcomes with propensity score analysis. Am Heart J. 2012;163:851-858.e1. DOI: 10.1016/j.ahj.2012.02.010

8. Aboulhosn J, Cabalka AK, Levi DS, Himbert D, Testa L, Latib A, et al. Transcatheter valve-in-ring implantation for the treatment of residual or recurrent tricuspid valve dysfunction after prior surgical repair. JACC Cardiovasc Interv. 2017;10:5363. DOI: 10.1016/j.jcin.2016.10.036

9. McElhinney $D B$, Cabalka AK, Aboulhosn $J A$, Eicken A, Boudjemline $Y$, Schubert $S$, et al. Transcatheter tricuspid valve-in-valve implantation for the treatment of dysfunctional surgical bioprosthetic valves: an international, multicenter registry study. Circulation. 2016;133:1582-1593. DOI: 10.1161/CIRCULATIONAHA.115.019353
10. Faurie $B$, Abdellaoui $M$, Wautot $F$, Staat $P$, Champagnac D, Wintzer-Wehekind J, et al. Rapid pacing using the left ventricular guidewire: reviving an old technique to simplify BAV and TAVI procedures. Catheter Cardiovasc Interv. 2016;88:988-993. DOI: $10.1002 / \mathrm{ccd} .26666$

11. Hilling-Smith $R$, Cockburn J, Dooley $M$, Parker J, Newton A, Hill A, et al. Rapid pacing using the 0.035 -in. retrograde left ventricular support wire in 208 cases of transcatheter aortic valve implantation and balloon aortic valvuloplasty. Catheter Cardiovasc Interv. 2017;89:783-786. DOI: $10.1002 / c c d .26720$

Cite this article as: Eitan $A$, Roguin A, Kerner A. Rapid Pacing Using the Guidewire During Transcatheter Tricuspid Valve-in-Valve Implantation. Structural Heart Disease 2017;3(5):157-162. DOI: https://doi. org/10.12945/j.jshd.2017.024.17 